\title{
Anesthetic management of schwannoma mimicking carotid body tumor
}

This article was published in the following Dove Press journal:

International Medical Case Reports Journal

28 August 2012

Number of times this article has been viewed

\section{Chitra Sivasankar \\ Department of Anesthesiology, Guthrie Clinic, Sayre, PA, USA}

Correspondence: Department of Anesthesiology, Guthrie Clinic, Sayre, PA 14440, USA

$\mathrm{Tel}+15708875583$

Fax + I5708874464

Email schitra12@hotmail.com
Abstract: Schwannomas are rare and slow-growing neurogenic tumors for which surgery is the standard of care. However, the anesthetic management of these tumors can be challenging. This case report describes the anesthetic management of a patient who underwent carotid endarterectomy and excision of a presumed carotid body tumor. Histopathologic examination showed that the excised tissue was a schwannoma, which in this location can mimic a carotid body tumor. The relevant literature is also reviewed.

Keywords: anesthesia, carotid body tumor splaying, head and neck tumor, schwannoma

\section{Introduction}

Schwannomas are benign nerve sheath tumors originating from motor and sensory nerves. They are slow growing tumors seen equally in both genders and in patients aged 20-50 years. They usually arise from the lower four cranial nerves or the cervical sympathetic chain in the parapharyngeal space. ${ }^{1}$ However, when they appear near the carotid sheath, they can masquerade as carotid body tumors. ${ }^{2}$ Both schwannomas and carotid body tumors usually have a long history, are asymptomatic, and show nonspecific signs on clinical examination. This can cause a diagnostic conundrum. ${ }^{1}$ In fact, the condition is often diagnosed only postoperatively after histopathologic examination. This case report concerns a patient who underwent carotid endarterectomy and excision of a presumed carotid body tumor, later identified as a schwannoma by histopathologic examination.

\section{Case report}

An 81-year-old man presented with sudden onset of numbness and weakness of the right hand. He had a medical history of myocardial infarction, atherosclerotic vascular disease, hypertension, and aortic stenosis. He had been initially investigated elsewhere for acute stroke. A carotid sonogram showed $60 \%-80 \%$ stenosis of the left internal carotid artery, $30 \%-50 \%$ stenosis of the right internal carotid artery, and bilateral plaques. There was also a large hypoechoic vascular mass at the supralateral aspect of the neck and lateral to the left carotid bifurcation measuring $5.2 \times 4.2 \times 4.4 \mathrm{~cm}$. When the patient was seen in our hospital, his weakness of the right hand had almost completely resolved.

Findings of clinical examination were unremarkable, except for a palpable mass at the left carotid bifurcation, measuring approximately $5 \mathrm{~cm}$ in diameter. Investigations showed a normal complete blood count, troponin level, and coagulation profile. 
Urine and serum vanillylmandelic acid levels were normal. An electrocardiogram showed marked left ventricular hypertrophy, and an echocardiogram showed moderate aortic stenosis $\left(1.1 \mathrm{~cm}^{2}\right)$, an ejection fraction of $50 \%$, and a transvalvular gradient of $45 \mathrm{mmHg}$. On computed tomography angiogram, the left carotid bulb region showed displacement of the bulb medially and anteriorly by a carotid body mass measuring approximately $5.5 \mathrm{~cm}$ superiorinferiorly and $4 \mathrm{~cm}$ transversely. High-grade stenosis was associated with a plaque involving the origin segments of the left internal carotid artery. The right carotid bulbar region showed a plaque and mild stenosis of less than $50 \%$ at the origin of the internal carotid artery and moderate stenosis in the $50 \%$ range at the origin of the external carotid artery. A preoperative selective carotid angiogram showed splaying of the carotid bifurcation (Figure 1). A feeding blood supply from the internal carotid and vertebral arteries was also noted. Because of the high-grade stenosis of the ipsilateral carotid artery, it was decided to perform simultaneous endarterectomy and tumor excision.

In view of the history of transient ischemic attack, urgent surgery was performed. A thorough assessment was performed to rule out catecholamine secretion and neurological deficits. After premedication with midazolam, a radial arterial line and a 16-gauge intravenous line were established. Cerebral oximetry was used to assess the adequacy of cerebral perfusion. Standard ASA monitoring preceded rapid sequence induction. After establishing an adequate depth of anesthesia, laryngoscopy was performed and the patient was intubated. Another large-bore intravenous access was obtained considering the possibility of heavy bleeding. The patient was ventilated with $50 \%$ oxygen, air, and isoflurane. During the initial phase of dissection, his blood pressure increased to $180 / 100 \mathrm{mmHg}$; this was brought under control by deepening the level of anesthesia

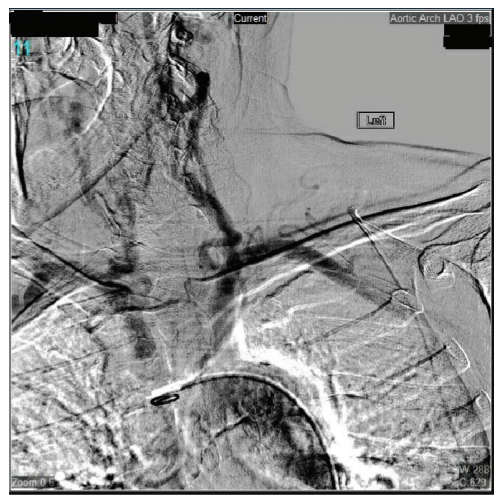

Figure I Splaying (widening) of carotid bifurcation by the mass. and administration of a bolus of sodium nitroprusside. During clamping of the carotid during endarterectomy, cerebral oximetry values decreased to $15 \%$ below baseline. The surgeon decided to use a shunt, and the oximetry values returned to baseline. Because of the fluctuations in blood pressure and the patient's history of coronary artery disease and aortic stenosis, the surgeon decided to infiltrate the carotid sinus with lidocaine. The patient was heparinized during the procedure to achieve an activated clotting time of 220 seconds. Uneventful endarterectomy was performed, and heparin was reversed with protamine. During the second part of removal of the carotid body tumor (Figure 2), the vascular surgeon was helped by an ear, nose, and throat surgeon. During the dissection, the patient experienced significant bleeding of $1000 \mathrm{cc}$, leading to a decrease in blood pressure to $70 / 50 \mathrm{mmHg}$, which was treated with fluid and phenylephrine boluses and infusion. Because the initial hemoglobin level was $16 \mathrm{gm} / \mathrm{dL}$, we did not perform a blood transfusion. During the final stages of excision, traction on the tumor led to a bradycardia of 35 , which was treated with atropine. After complete excision of the tumor, the patient remained hemodynamically stable. Blood gas analysis showed $\mathrm{pH}$ of 7.4, $\mathrm{PaO}_{2}$ of $294 \mathrm{mmHg}, \mathrm{PaCO}_{2}$ of $39 \mathrm{mmHg}$, and hemoglobin of $12 \mathrm{gm} / \mathrm{dL}$. At the end of the procedure, the patient was reversed and extubated wide awake. He showed no neurological deficits during the postoperative period and was discharged 3 days later.

\section{Discussion}

The most common mass in the carotid bifurcation is a carotid body tumor. The differential diagnosis of a parapharyngeal mass includes schwannoma, cervical lymphadenopathy, parotid mass, carotid body aneurysm, metastatic tumor, and brachial cleft cyst. Fewer than 100 cases of cervical sympathetic chain schwanomma are

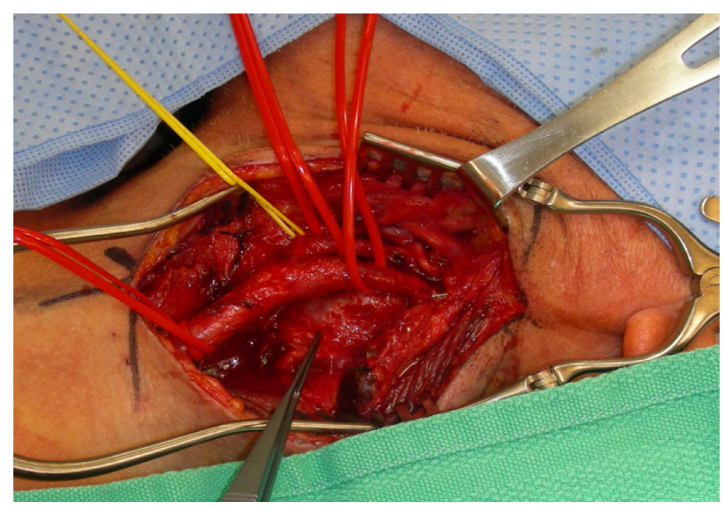

Figure 2 Surgical field showing the relationship of the mass to the carotid bifurcation. 
reported in the literature. ${ }^{2}$ Schwannomas always cause a diagnostic challenge due to their nonspecific clinical signs. Most often the diagnosis is made postoperatively after histopathologic examination. Our patient had a slow-growing pulsatile mass in the carotid bifurcation area, first diagnosed as a carotid body tumor. However, after resection, the tumor was found to be a schwannoma.

Patients who present with tumors in the upper neck mimicking a carotid body tumor are usually managed as such. The characteristic sign of a carotid body tumor, known as the Lyre sign, is splaying of the carotid artery on an angiogram. ${ }^{3}$ However, other tumors may occasionally present this sign. ${ }^{4}$ Carotid body aneurysm is a known differential diagnosis, so fine needle aspiration is not advisable. ${ }^{5}$ Ultrasound, computed tomography scan, and magnetic resonance imaging are useful for assessing the extent of the mass. Angiography is useful to assess both the carotid circulation and vascularity of the mass, and to rule out a contralateral tumor. ${ }^{6}$ Arteriography is useful for preoperative embolization of feeding vessels. Surgical removal is the standard treatment. Preoperative tumor embolization can shrink the size of the mass and reduce complications in selected patients. However, tumor embolization is not routinely used because of the potential risk of reflux of particles into the ophthalmic and cerebral circulation. ${ }^{7}$ The standard technique for surgery includes wide exposure, identification and preservation of the neurovascular structures, tumor dissection, shunting, and grafting when required. ${ }^{8}$

Anesthetic management of patients with a diagnosis of carotid body tumor can be challenging because of bleeding, cranial nerve palsies, cerebrovascular accident, labile blood pressures, postoperative hypoxia, and Horner's syndrome. A thorough preoperative assessment includes a careful history, physical examination, and serum and urine estimation of catecholamines. Paragangliomas in the region can release norepinephrine, serotonin, kallikrein, and histamine. Administration of alpha-blockers followed by beta-blockers may be used preoperatively to lower blood pressure in patients with high catecholamine levels. Intraoperative release of histamine and bradykinin can lead to intractable hypotension and shock. This can be treated by somatostatin analogs. ${ }^{9}$ Cranial nerve palsies and Horner's syndrome can occur due to nerve infiltration, nerve damage during surgery, or edema after surgery. ${ }^{12}$ The incidence of neurological damage is usually around $60 \%$ with cranial nerves VII, IX, X, and XII. ${ }^{10}$ With cervical sympathetic chain schwannoma resection, the incidence of Horner's syndrome is high. ${ }^{11}$ Injuries to these nerves can lead to airway obstruction, aspiration, dysphagia, and dysphonia. ${ }^{14}$
It is important to consider the possibility of life-threatening bleeding. Large-bore intravenous access, an arterial line, and Foley catheterization are hence advised. Depending on the size of the tumor and extent of involvement, a central venous may be indicated. ${ }^{13}$ Reflex bradycardia and hypotension can occur with carotid sinus stimulation, which can be treated with atropine or infiltration around the carotid sinus with a local anesthetic. Manipulation of these carotid body masses can also lead to a dangerous rise in blood pressure. This can be controlled by deepening the anesthesia or by administration of vasodilators such as nitroprusside and phentolamine. Baroreceptor failure can occur from denervation of carotid arteries, which can lead to intractable hypertension resulting in stroke or myocardial infarction. ${ }^{16}$ Depending on the extent of the mass, the carotid artery may have to be clamped for the procedure. During this time, it is important to ensure that contralateral circulation is adequate to prevent cerebral ischemia. Several methods for monitoring cerebral ischemia are useful in this situation, ie, electroencephalography, cerebral oximetry, somatosensory evoked potential, transcranial Doppler jugular oxygen saturation, and measurement of distal carotid stump pressure. ${ }^{15}$ Raising blood pressure to improve collateral flow can prevent or reverse changes on the electroencephalogram and thus avoid ischemic injury. ${ }^{13}$

First-bite syndrome resulting from loss of sympathetic innervation of the parotid gland has been described postoperatively. ${ }^{17}$ This can manifest as severe pain in the jaw and ear on taking the first bite of food. Different treatment options have been tried for this condition, such as amitriptyline, carbamazepine, pregabalin, tympanic neurectomy, and botulinum toxin injections, with variable results. ${ }^{18,19}$ Recently, there has been a report of Pourfour $\mathrm{du}$ Petit syndrome after excision of a cervical chain schwannoma. This syndrome results from overstimulation of the sympathetic chain and manifests with features that are in contrast with those of Horner's syndrome. ${ }^{20}$

In summary, patients presenting with a parapharyngeal mass mimicking carotid body tumors are managed similar to patients with carotid body tumors. Anesthetic management of these tumors can be challenging.

\section{Disclosure}

The author reports no conflict of interest in this work.

\section{References}

1. Panneton JM, Rusnak BW. Cervical sympathetic chain schwannomas masquerading as carotid body tumors. Ann Vasc Surg. 2000;14: 519-524. 
2. Uzun L, Ugur MB, Ozdemir H. Cervical sympathetic chain schwannoma mimicking a carotid body tumor: a case report. Tumori. 2005;91: 84-86.

3. Patlola R, Ingraldi A, Walker C, Allie D, Khan IA. Carotid body tumour. Int J Cardiol. 2009;143:7-10.

4. Shirakura S, Tsunoda A, Akita K, et al. Parapharyngeal space tumors: anatomical and image analysis findings. Auris Nasus Larynx. 2010;37: $621-625$.

5. Matticari S, Credi G, Pratesi C, Bertini D. Diagnosis and surgical treatment of the carotid body tumors. J Cardiovasc Surg. 1995;36: 233-239.

6. Carrau R, Myers E, Johnson J. Management of tumors arising in the parapharyngeal space. Laryngoscope. 1990;100:583-589.

7. Casasco A, Houdart E, Biondi A, et al. Major complications of percutaneous embolization of skull-base tumors. AJNR Am J Neuroradiol. 1999;20:179-181.

8. Moukarbel RV, Sabri AN. Current management of head and neck schwannomas. Curr Opin Otolaryngol Head Neck Surg. 2005;13: 117-122.

9. Pasternak J, Lanier W Jr. Diseases of the Autonomic and Peripheral Nervous Systems. Stoelting's Anesthesia and Co-Existing Disease. 5th ed. Philadelphia, PA, USA: Churchill Livingstone; 2008;10: 251-252.

10. Malone JP, Lee WJ, Levin RJ. Clinical characteristics and treatment outcome for nonvestibular schwannomas of the head and neck. Am J Otolaryngol. 2005;26:108-112.

11. Valentino J, Boggess MA, Ellis JL, Hester TO, Jones RO. Expected neurologic outcomes for surgical treatment of cervical neurilemomas. Laryngoscope. 1998;108:1009-1013.
12. Wax MK, Shiley SG, Robinson JL, Weissman JL. Cervical sympathetic chain schwannoma. Laryngoscope. 2004;114:2210-2213.

13. Gupta B, Mitra J. The anesthetic management of chemodectoma excision. The Indian Anesthetists Forum, 2007. Available from: http:// www.theiaforum.org/Article_Folder/anaesthetic-management-ofchemodectoma-excision.pdf. Accessed August 2, 2012.

14. Biswas D, Marnane CN, Mal R, Baldwin D. Extra cranial head and neck schwannomas - a 10-year review. Auris Nasus Larynx. 2007;34: 353-359.

15. Lam AM, Manninen PH, Ferguson GG, Nantau W. Monitoring electrophysiologic function during carotid endarterectomy: a comparison of somatosensory evoked potentials and conventional electroencephalogram. Anesthesiology. 1991;75:15-21.

16. Maturo S, Brennan J. Baroreflex failure: a rare complication of carotid paraganglioma surgery. Laryngoscope. 2006;116:829-830.

17. Trenery A, Qureshi ZP, Rowen R, Day T, Norris L, Bennett CL. First-bite syndrome: a novel complication of carotid body paraganglioma resection. Community Oncol. 2001;8:375-378. Aug 2011.

18. Casserly P, Kiely P, Fenton JE. Cervical sympathetic chain schwannoma masquerading as a carotid body tumour with a postoperative complication of first-bite syndrome. Eur Arch Otorhinolaryngol. 2009; 266:1659-1662.

19. Netterville JL, Jackson CG, Miller FR, Wanamaker JR, Glasscock ME. Vagal paraganglioma: a review of 46 patients treated during a 20-year period. Arch Otolaryngol Head Neck Surg. 1998;124:1133-1140.

20. Boros MJ, Wysong ST. Syndromes after resection of a cervical schwannoma. Ear Nose Throat J. 2011;90:431-433.
International Medical Case Reports Journal

\section{Publish your work in this journal}

The International Medical Case Reports Journal is an international, peer-reviewed open-access journal publishing original case reports from all medical specialties. Previously unpublished medical posters are also accepted relating to any area of clinical or preclinical science. Submissions should not normally exceed 2,000 words or

\section{Dovepress}

4 published pages including figures, diagrams and references. The manuscript management system is completely online and includes a very quick and fair peer-review system, which is all easy to use. Visit $\mathrm{http}: / /$ www.dovepress.com/testimonials.php to read real quotes from published authors. 